\title{
BUILDING AN ECOSYSTEM FOR A NEW ENGINEERING PROGRAM
}

\author{
Wieslaw GREBSKI \\ The Pennsylvania State University \\ Michalene Eva GREBSKI \\ Northampton Community College
}

\begin{abstract}
:
Penn State Hazleton has recently developed and implemented a new Engineering program with a focus on energy efficiency and energy sustainability. To accelerate the implementation cycle of the program, it was necessary to very rapidly create and establish the components of an ecosystem needed for the Engineering program to prosper and grow. This paper describes the individual components of the ecosystem as well as the methods used to establish them. The paper also discusses the different initiatives to increase enrollment as well as placement rates for graduates. Continuous quality improvement procedure applied to maintain the quality of the program is also being discussed.
\end{abstract}

Key words: program implementation, Engineering program ecosystem, student recruitment, student placement

\section{INTRODUCTION}

Many Engineering programs in the United States are struggling with recruitment and retention issues. Many students entering the freshman year have insufficient Math and Physics backgrounds and require extensive remediation [4]. Even with remedial courses being available, the retention rate is low. Those problems are affecting even more severely new-established academic Engineering program [5]. High school guidance personnel are not familiar with those programs, so they promote well-established programs better. New academic programs are also less known to industry. Industry is more likely to recruit graduates from Engineering programs they are familiar with. The well-established Engineering programs have the ecosystem already developed. Implementation of new academic Engineering programs requires extended outreach activities on behalf of those programs [1]. This is needed to speed-up the development of the ecosystem which is necessary for the program to prosper and grow. This ecosystem would eventually develop through a natural process, but this could take one or two decades. University and community leaders are expecting the implementation of a new academic program to take place within five academic years. This requires extensive outreach activities on behalf of the program faculty to speed-up building of an ecosystem and have all the essential partners cooperating and supporting the program.

\section{MAJOR COMPONENTS OF THE ECOSYSTEM FOR AN ENGI- NEERING PROGRAM}

Academic Engineering programs cannot exist in isolation. It would be like a single tree planted in the middle of the desert. Academic Engineering programs require the entire ecosystem to prosper and be effective. The compo- nents of the ecosystem of the Engineering program are as follows:

1. Cooperation with Industry.

Industry provides internship opportunities for students and topics for Engineering projects. Industry also provides employment opportunities for graduates and research opportunities for faculty. Industry is the place where academic Engineering programs gathers information on current industrial practices. This is needed in order to keep the curriculum current and aligned with the demands of industry. Industry needs the university to provide them with well-educated engineers who are ready to meet their needs with minimal additional training. The cooperation between the academic programs at the university and industry is beneficial and is absolutely needed by both partners. One cannot properly function without the other. Well-established academic Engineering programs have those links already developed. This process takes some time from ten to fifteen years. New academic Engineering programs, however, cannot wait that many years for those links to develop naturally. This process can be accelerated by putting an emphasis on outreach and actively seeking and recruiting industry partners.

2. Cooperation with a Business Incubator Center.

Cooperation between an Engineering program and a business incubator center is a unique opportunity to enhance the students' educational experience. A business incubator center can be used as a "learning factory" and "teaching laboratory". The clients of the business incubator center can be role models to Engineering students from the perspective of innovativeness and creativity. Cooperation with a business incubator center creates opportunities to engage Engineering students in 
real world problem solving. This would be difficult to accomplish in the classroom. Getting Engineering students involved in working on multidisciplinary teams allows them to develop communication skills and teaches them how to become a team player. The skills to be an effective communicator and team player are what modern manufacturing and research and development companies are looking for. Establishing the cooperation between an academic Engineering program and business incubator center is not a difficult task, but it requires initiative on the part of the Engineering program.

3. Cooperation with Local School Districts as a Part of the Ecosystem.

Cooperation with local school districts is very important from the perspective of recruiting high school graduates into an Engineering program [3]. In the United States, only $10 \%$ of high school graduates pursue Engineering and related careers. In comparison, those numbers are much higher in other countries (20\% in Germany and Japan). To promote a new Engineering program, an extensive outreach to secondary schools is needed to increase the awareness of Engineering as a profession and then promote the new Engineering program. The Engineering faculty also offers in-service training courses for K-12 teachers and guidance personnel for local school districts [6]. The Engineering faculty gets also involved as guest speakers during career days. Penn State Hazleton also sponsored "Regional Research Fair" for high school students. The winners of that research fair get a partial scholarship to attend Penn State Hazleton.

4. International Cooperation as a Part of the Ecosystem. No Engineering program can stay on the cutting edge of technology without international cooperation. International cooperation allows for student and faculty exchange as well as joint research projects. In today's global society, it is very important to provide students with the multinational and multicultural aspects of education. International cooperation allows to share the best practices and provide the students with skills of working on diverse multinational and multicultural teams. International cooperation is a part of the ecosystem for Engineering programs. To speed-up the process of international cooperation, the newly established Engineering program at Penn State Hazleton developed cooperation with the University d' Artois in France. French students were periodically visiting Penn State Hazleton and Penn State Hazleton students attended programs at the University d' Artois in France [7]. There were also some faculty visits. International collaboration also helps with the recruitment of international students.

5. Alumni as a Part of an Ecosystem.

The Pennsylvania State University has a very strong alumni association. Alumni are a very important part of an ecosystem for academic Engineering programs. They can be a major asset for every academic program. To maintain contact with alumni, Penn State Hazleton started an annual Engineering alumni reunion at the Hazleton Campus. This alumni reunion was a weekend activity. During that time, senior level students are presenting their capstone design projects in front of the alumni. Every year there is also a joint dinner with graduating students and the alumni. Alumni can be very helpful in providing career guidance to graduating stu- dents. Alumni can also provide assistance to graduating students in finding employment opportunities. The annual alumni reunion at Penn State Hazleton has become a very popular and well attended event. Very often alumni have provided ideas for student projects. Some alumni were instrumental in making arrangements for industry to donate some laboratory equipment (3-D printers, etc.).

6. University Relations Office as a Part of an Ecosystem. The University Relations Office is coordinating fundraising activities for the University as well as publish relations. This office can help in securing funds for laboratory equipment as well as funds for student scholarships. Even partial scholarships for students can significantly help with student recruitment and retention. This is very important for newly established Engineering programs. The University Relations Office can also help in preparing press releases promoting newly established Engineering programs. They can also help in preparing and printing some promotional materials which can be used in marketing a newly established program. It is important for new Engineering programs to immediately establish cooperation with the University Relations Office.

7. Other Educational Institutions and Training Programs. Other educational institutions like local community colleges can be very valuable partners of the ecosystem. They can be a source of transfer students. The newly established Engineering program at Penn State Hazleton has signed articulation agreements with three community colleges. Those articulation agreements were focused on the transferability of credits and courses from the Pre-Engineering programs at the community colleges to the newly established Engineering program at Penn State Hazleton. The articulation agreements with community colleges has significantly helped to increase enrollment in the Engineering program at Penn State Hazleton. Approaching community colleges and including them into the ecosystem of the Engineering program early enough in the stage of program implementation shortened the implementation cycle. It also allows the Engineering program to accept a leadership role in workforce development.

8. Local Community as a Part of the Ecosystem.

The local community can be an important part of the ecosystem for an Engineering program. Building an awareness in the local community can be a very effective method of promoting the program as well as recruiting future students. The newly established Engineering program at Penn State Hazleton organized an annual Community Day at the end of the Spring semester. It was like an Open House for the local community. Student projects can be showcased at that event. There are also art and craft as well as some science activities for children. Community Day is an excellent opportunity to promote community support for a newly established Engineering program.

9. Federal, State and Local Governments as a Part of the Ecosystem for the Engineering Program.

Federal, state and local governments have a vested interest in promoting economic growth as well as workforce development. They can be very valuable partner in the newly established Engineering program. It is important to establish contacts with government agencies. Very often there are funding opportunities for work- 
force development. Including government agencies into the Engineering program ecosystem can periodically benefit the program.

\section{ESTABLISHING AN INDUSTRIAL ADVISORY COUNCIL}

The Industrial Advisory Council (IAC) is a committee comprised of leaders from local industry. The Industrial Advisory Council represents prospective and future employers of graduates from the academic Engineering program. Very often the Industrial Advisory Council is being established while the Engineering program is in the development stage. The role of the Industrial Advisory Council is to provide feedback from industry while the Engineering curriculum is being developed. The establishment of the Industrial Advisory Council is required by the Engineering accrediting agency, ABET (Accrediting Board for Engineering and Technology), if the Engineering program is planning to seek accreditation. The Industrial Advisory Council is required to meet at least once during every semester. IAC reviews once a year the program curriculum and suggests adjustments needed to comply with the expectations of industry. IAC also conducts interviews with graduating students for collecting their perspective on the quality of the education they received and their satisfaction from the program. The IAC provides the Engineering Program Coordinator the results of the graduates' feedback for the purpose of continuous quality improvement.

\section{OUTREACH INITIATIVES TO INSURE QUALITY AND QUAN- TITY OF INCOMING STUDENTS}

As a part of the outreach, Penn State Hazleton offers for high school students "Introduction to Engineering Design" (EDSGN 100) as a part of the dual enrollment initiative. Dual enrollment allows senior high school students to take one college course while they are in high school. The Engineering Department at Penn State Hazleton offers EDSGN 100 at four different high schools in the region. High school students are paying for that course at a discounted by $75 \%$ rate. (Students are paying $25 \%$ of the tuition.) As a part of that course, students learn the concepts of engineering design and graphics including solid modeling using ACAD. There is a design project as a part of that course. Students learn the concept of structural analysis. They also learn the concept of factor of safety and get some background on engineering analysis. During the class, students also learn how mathematics, physics and chemistry apply to engineering. There was also a hands-on part of the project focusing on the building of a prototype based on the design. The dual enrollment class (EDSGN 100) was offered by the Engineering Department to high school students at four different school districts. Approximately $25 \%$ of the students taking the course enrolled in the newly established Engineering program at Penn State Hazleton. To maintain local school districts as a part of the ecosystem, the dual enrollment classes need to be offered on an ongoing basis $[1,3]$.

\section{OUTREACH INITIATIVES TO SECURE EMPLOYMENT FOR GRADUATES}

The employment rate of graduates from any academic program is the main factor in assessing the program's success. The employment rate of graduates is being used in promoting the program. Every academic program in the United States is required by law to collect the employment rate of its graduates. That data is available to the public including future students and their parents. In addition to the employment rate, academic programs are also collecting data on the average starting salaries. It was very important for the new Engineering program at Penn State Hazleton to have as high as possible placement rate and starting salaries. To accomplish this, the Engineering faculty was actively involved in promoting the program and its graduates as follows:

- to use as capstone design projects real world highly visible projects,

- to make student projects accessible by industry,

- to encourage junior and senior level students to attend as many job fairs as possible,

- to encourage senior level students to participate in the Engineering alumni reunion to facilitate networking,

- to have senior level students attending professional conferences,

- to introduce every senior level student to the Industrial Advisory Council.

The first and second graduating class for the new Engineering program focusing on energy efficiency and energy sustainability had a $100 \%$ employment rate with a $\$ 65,000$ annual gross starting salary. This fact makes the program more attractive to prospective students and leads to an increase in enrollment. It is important to control the growth of the program and keep the program aligned with the demand of industry. Controlling the growth of the program also allows to maintain the quality expected by industry.

\section{CONTINUOUS QUALITY IMPROVEMENT PROCEDURE FOR THE COURSES AND THE ENGINEERING PROGRAM}

Continuous quality improvement (CQI) is an important part of every academic program. It allows the program to stay aligned with the expectations of industry [2]. At the newly-established Engineering program at Penn State Hazleton, there is a CQI procedure at the course level (semester course review) and a CQI procedure on the program level (annual program assessment).

\section{Semester Course Review}

After each semester, each faculty member teaching an Engineering course is required to prepare a written evaluation of the effectiveness of their course(s) in achieving the expected outcomes of the course(s). Those evaluations are based on data collected in the measurement and evaluation process as well as other observations of the faculty. The faculty can identify any challenges in achieving the expected course outcomes as evidenced by data. If some challenges are identified the report also identifies the anticipated action for improvement. The future course assessments always evaluate the effectiveness of the past changes and improvements. Copies of those reports are maintained by the Engineering Program Coordinator. A schematic diagram of the semester course reviews is shown in Fig. 1.

\section{Annual Program Assessment}

At the end of each academic year, the Engineering Program Coordinator prepares a written report assessing the performance of the Engineering program with respect to the expected student outcomes. This report uses the course reports prepared by the faculty and aggregated the course and program data collected from the measurement and evaluation system. The purpose of the report is similar 
to the course evaluation to identify potential challenges, to define action for improvement and monitor the effective- ness of the implemented changes. The schematic diagram of the annual program assessment is shown in Fig. 2.

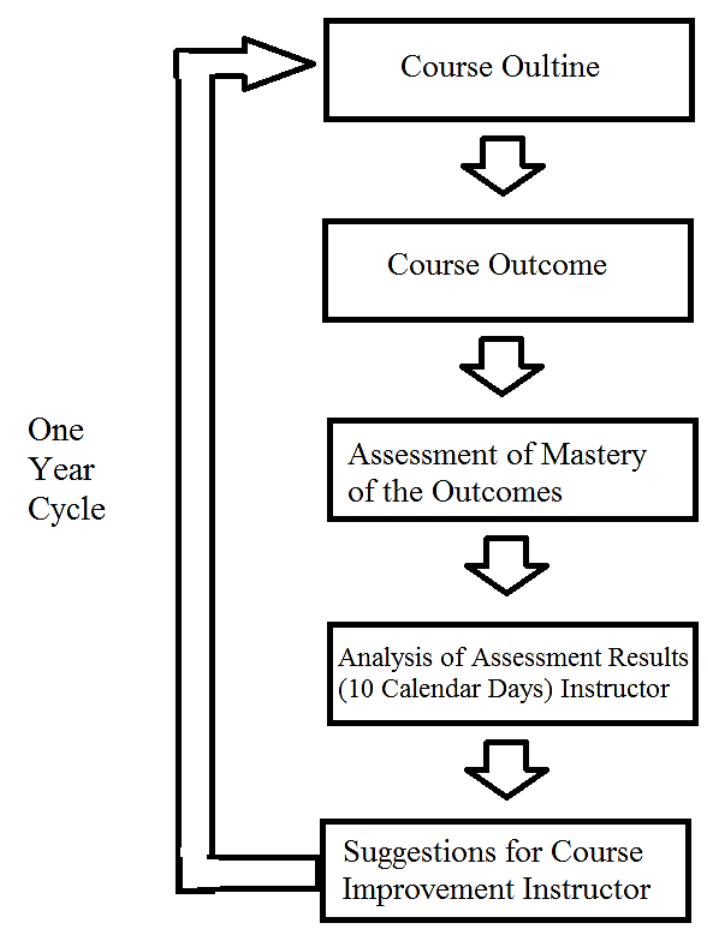

Fig. 1 Flowchart of the semester course review

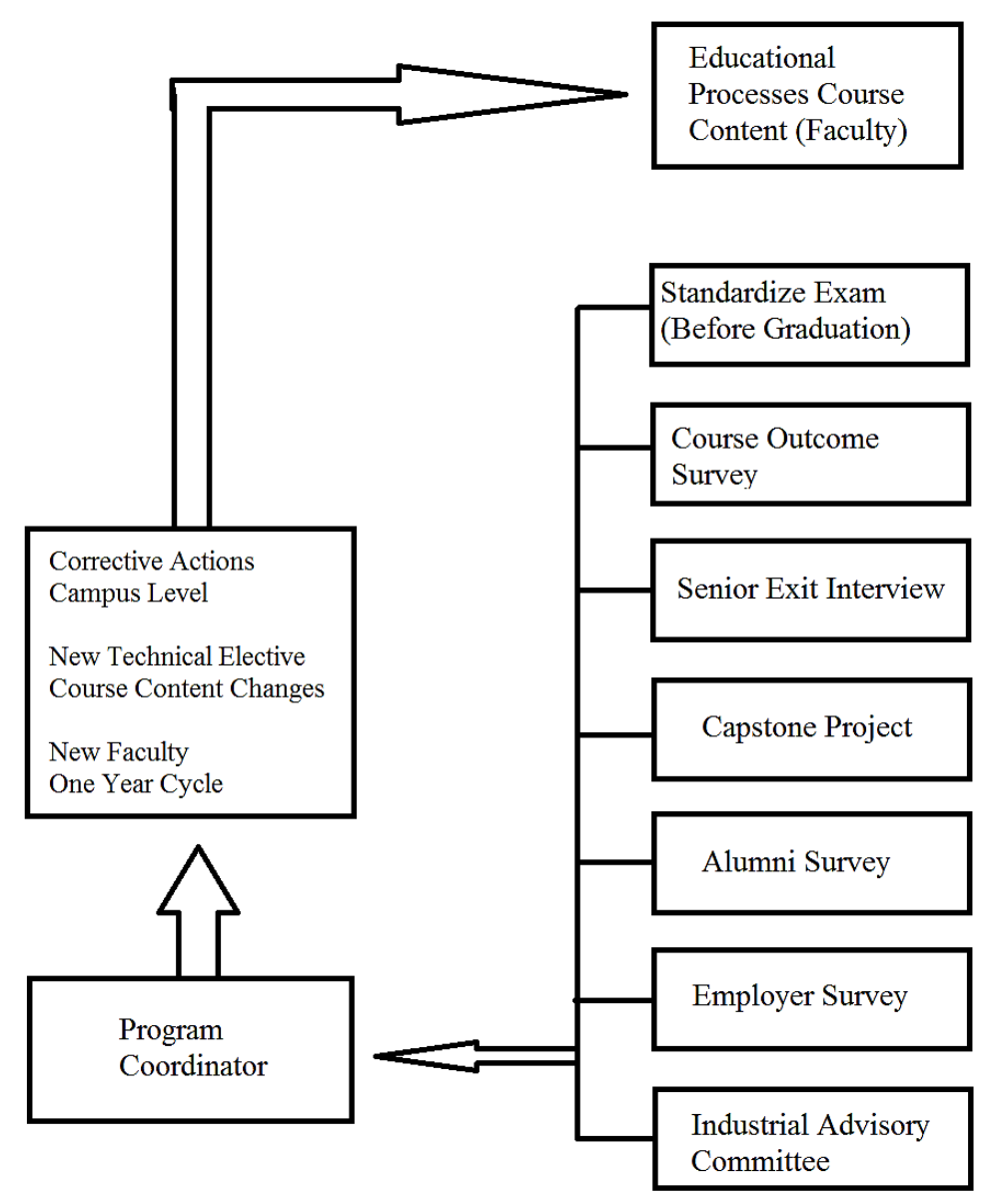




\section{CONCLUSIONS}

The introduction of a new academic Engineering program requires skills and dedication on behalf of the program's faculty. Outreach activities are very time-consuming and require good coordination to be effective. The most time-consuming and difficult task is to secure the pipeline of incoming well-prepared students. Offering dual enrollment courses for high school students is an effective method of recruitment. It creates, however, faculty overload. Hiring part-time faculty to teach dual enrollment courses seems to be a good solution.

\section{REFERENCES}

[1] S. Cai and W. Grebski. "Improve Retention through Implementation of "Toy FUN « Projects into Fundamental Engineering Classes", in Proc. IAJC-ASEE, Joint International Committee, 2011.

[2] W. Grebski and M. Grebski. "Keeping Technical Education Aligned to the Needs and Expectations of Industry. Management Systems in Production Engineering, vol. 22(2), pp. 77-80, 2016. DOI:10.12914/MSPE-01-02 -2016 .

\footnotetext{
Wieslaw Grebski, Professor Emeritus

The Pennsylvania State University

76 University Drive, Hazleton, PA 18202, USA

e-mail:wxg3@psu.edu

\section{Michalene Eva Grebski, Adjunct Instructor}

Northampton Community College - Monroe Campus, USA

e-mail:mgrebski@northampton.edu
}

[3] W. Grebski and S. Cai. "Partnership with STEM High School as a Recruiting Tool for Engineering Program", in Proc. The $10^{\text {th }}$ Latin American and Caribbean Conference for Engineering and Industry, 2012.

[4] W. Grebski. "Teaching Mathematics as a Global Challenge for Engineering Education", in Proc. ICIE Conference, 2015.

[5] W. Grebski. "Recruitment of Engineering Students through Community-Based Programs", in Proc. The $12^{\text {th }}$ Latin American and Caribbean Conference on Engineering and Industry, 2014.

[6] W. Grebski and K. Dudeck. "Portable Photovoltaic Laboratory for In-Service Teacher Workshops", in Proc. Annual Conference American Society for Engineering Education, 2013.

[7] W. Grebski. "Energy Sustainability from an Engineering and Business Perspective", in Proc. Intensive Program: Sustainability Management and Technology International Conference, 2012. 